\title{
Research on mutual driving development of financial ecology and economic growth in Jiangsu province--analysis based on coupled
}

\author{
model
}

Haitao Wang

School of Economic \& Management, Nanjing University of Science \& Technology, China

*Corresponding author: Haitao Wang, master, 1275293295@qq.com

\begin{abstract}
Based on the data of Jiangsu Province from 2006 to 2015, a three-system coupling model is constructed. The coupling degree and the coupling coordination degree are used as the evaluation indexes. The coupling coordination between the financial system and the economic growth system of the dynamic evolution mechanism of relationship in Jiangsu Province is analyzed empirically. The results show that the coupling level of the three systems is closely related to the degree of coupling between the financial entity, the financial environment, the financial subject-the economic growth and the financial environment-economic growth.
\end{abstract}

Key words: financial subject; financial environment; financial ecology; economic growth; coupling

\section{Introduction}

Financial ecology is a bionic concept, first proposed by the People's Bank of China Governor Zhou Xiaochuan, emphasizing the external environment from the development of the financial industry, not just from their own consideration of the development of the financial system in the process of risk. The concept of a proposed, followed in the macro financial sector set off a wave of understanding of China's financial development, and formed two major points: "financial ecological environment" and "financial ecological system view."

The so-called coupling refers to the phenomenon that two or more systems interact with each other through various interactions. It is a dynamic association between interdependence, mutual coordination and mutual driving under the benign interaction among the subsystems. Coupling as a physical concept, is now widely used in biology, geography, environmental and other fields. 


\section{Experimental}

\subsection{Index system construction}

In order to establish the comprehensive index system of economic growth-financial ecosystem, this paper refers to the research results of a large number of scholars and forms a preliminary framework ${ }^{1}$. On the basis of this, the selection of indicators should follow the following principles: I selected indicators should reflect the financial ecological and economic growth between the constraints of stress constraints; II financial ecology and economic growth are closely linked, select the indicators to a comprehensive system, structured; III financial ecology and economic growth is the process of dynamic development, select the indicators should have a timeliness and stage $\mathrm{e}^{2,3}$. On the basis of following the above principles, this paper has further set up and screen the indicators. Finally, a total of 13 first-level indicators (criterion layer), 42 secondary indicators (index layer), the specific relationship between the indicators of the system, see Table 1.

Table 1 - Jiangsu Province financial subject - financial environment - economic growth index system

\begin{tabular}{|c|c|c|c|}
\hline Target layer & Criteria layer & Index layer & Indicator explanation or unit \\
\hline \multirow{13}{*}{$\begin{array}{l}\text { Financial } \\
\text { Subject }\end{array}$} & \multirow{7}{*}{ Financial Scale } & Bank financial institutions outlets & \\
\hline & & Securities financial institutions outlets & \\
\hline & & Financial practitioners & \\
\hline & & Financial correlation & $\begin{array}{l}\text { The sum of direct financing and } \\
\text { indirect financing /GDP }\end{array}$ \\
\hline & & Insurance density & Premium / Total population \\
\hline & & Insurance depth & Premium /GDP \\
\hline & & Listed company & \\
\hline & \multirow{3}{*}{$\begin{array}{l}\text { Financial } \\
\text { Structure }\end{array}$} & Direct financing ratio & $\begin{array}{l}\text { Direct financing amount / total } \\
\text { financing amount }\end{array}$ \\
\hline & & Equity financing ratio & $\begin{array}{l}\text { Equity financing / direct } \\
\text { financing }\end{array}$ \\
\hline & & Debt financing ratio & Debt financing / direct financing \\
\hline & \multirow{3}{*}{$\begin{array}{l}\text { Financial } \\
\text { Efficiency }\end{array}$} & Deposit and loan ratio & Loan / deposit \\
\hline & & Financing conversion rate & $\begin{array}{l}\text { Direct Financing / Fixed Assets } \\
\text { Investment }\end{array}$ \\
\hline & & Asset securitization rate & $\begin{array}{l}\text { Total turnover of securities } \\
\text { business department/GDP }\end{array}$ \\
\hline
\end{tabular}

Limited to space, this article does not list the remaining index system, if necessary, the reader can contact the author.

\subsection{Data normalization}

Between the indicators due to the different dimensions and magnitude of the different, there is non-commensurability. In order to facilitate our comprehensive evaluation of the indicators, 
the collected data need to be dimensionless to eliminate the effects of different orders of magnitude and dimensions. Here we use extreme value processing, see equations (1) and (2):

$$
\begin{aligned}
X_{i j}^{*} & =\frac{X_{i j}-\min _{i}\left\{X_{i j}\right\}}{\max _{i}\left\{X_{i j}\right\}-\min _{i}\left\{X_{i j}\right\}} \\
X_{i j}^{*} & =\frac{\max _{i}\left\{X_{i j}\right\}-X_{i j}}{\max _{i}\left\{X_{i j}\right\}-\min _{i}\left\{X_{i j}\right\}}
\end{aligned}
$$

Where $X_{i j}$ represents the $\max _{i}\left\{X_{i j}\right\}-\min _{i}\left\{X_{i j}\right\}$ values of the jth index in all years, $X_{i j}^{*} \in[0$, $1]$.

\subsection{Determination of the weight of the index}

We use the entropy method to determine the weight of each indicator (see Appendix 1), that is, according to the value of each indicator of the amount of information provided to determine the size of the weight. The calculation steps are as follows:

(1) The j-th index in the first year of the characteristics of the proportion:

$$
P_{i j}=X_{i j}^{*} / \sum_{i=1}^{n} X_{i j}^{*}\left(X_{i j}^{*} \geq 0, X_{i j}^{*} \geq 0\right),
$$

(2) Entropy of the j-th index:

$$
e_{j}=-\frac{1}{L N n} \sum_{i=1}^{n} P_{i j} L N\left(P_{i j}\right)\left(0 \leq e_{j} \leq 1\right),
$$

(3) The difference coefficient of index $\boldsymbol{X}_{\boldsymbol{j}}$ :

$$
g_{j}=1-e_{j}
$$

(4) Indicator weight:

$$
w_{j}=g_{j} / \sum_{i=1}^{m} g_{j}
$$

Where $\mathrm{m}$ represents the number of indicators and $\mathrm{n}$ represents the number of years.

\subsection{Coupling model}

\subsubsection{Composite index calculation}

The financial evaluation of the financial entity, the financial environment and the economic growth system is described as follows:

$$
\begin{aligned}
& \mathrm{f}(\mathrm{x})=\sum_{j=1}^{m} x_{i j}^{*} \times w_{j} \\
& \mathrm{~g}(\mathrm{y})=\sum_{j=1}^{m} y_{i j}^{*} \times w_{j} \\
& \mathrm{~h}(\mathrm{z})=\sum_{j=1}^{m} z_{i j}^{*} \times w_{j}
\end{aligned}
$$

Where $\mathrm{m}$ is the number of indicators in the agglomeration system, $\boldsymbol{x}_{\boldsymbol{i} \boldsymbol{j}}^{*}$ is the normalized value of the jth indicator in the financial system, and $\boldsymbol{y}_{\boldsymbol{i} j}^{*}$ is the normalized value of the $\mathrm{j}$-th indicator in the financial environment system, $\boldsymbol{z}_{\boldsymbol{i} \boldsymbol{j}}^{*}$ is the normalized value of the jth index in the financial environment system, and $\boldsymbol{w}_{j}$ is the weight of the jth index. The higher the calculated value, the better the agglomeration situation. 


\subsubsection{Coupling coordination calculation}

Based on the capacity coupling concept and the capacity coupling coefficient model in physics, we get a couple of system or factor interaction coupling models. The coupling model of the three systems is derived from the two-system coupling model. The model is as follows:

$$
C_{0}=\frac{f(x) g(y)+f(x) h(z)+g(y) h(z)}{f^{2}(x)+g^{2}(y)+h^{2}(z)}
$$

Among them, $C$ is the financial entity, financial environment and economic growth system three system coupling degree. Similarly, because the coupling degree model, can only explain the strength of the interaction, can not reflect the level of coordinated development. Therefore, the coupling degree coordination model is introduced to better evaluate the degree of coupling coordination of any two systems. The formula is as follows:

$$
\mathrm{D}_{o}=\sqrt{C_{0} \times T_{0}} \text {, where } T_{0}=\alpha \mathrm{f}(\mathrm{x})+\beta \mathrm{g}(\mathrm{y})+\gamma \mathrm{h}(\mathrm{z})
$$

In this paper, $\boldsymbol{C}_{\mathbf{0}}$ is the coupling degree, $\boldsymbol{T}_{\mathbf{0}}$ is the comprehensive evaluation index of the financial subject-financial environment agglomeration, $\alpha, \beta, \gamma$ is the undetermined coefficient, that is, the weight of the subsystem development level. In order to understand the mechanism of the mutual drive of the two systems, $\alpha=\beta=\gamma=1 / 3$.

Compared with the coupling model, the coupled coordination degree model has higher stability and wider application range. It combines the two systems to coordinate the situation and the two areas in which the level of economic development. The higher the degree of coupling development, the higher the overall level of the development of the two systems, and the more harmonious the coupling between the two systems ${ }^{4}$. The criteria for determining the coupling coordination value calculated from the above formula are as follows:

Table 2 - Coupling Coordination Level Classification Criteria

\begin{tabular}{ccl}
\hline Number & D value & Coordination level \\
\hline 1 & $0.00-0.09$ & Extreme disorder \\
2 & $0.10-0.19$ & Serious disorder \\
3 & $0.20-0.29$ & Moderate disorder \\
4 & $0.30-0.39$ & Mild disorder \\
5 & $0.40-0.49$ & On the verge of imbalance \\
6 & $0.50-0.59$ & Reluctantly coordinated \\
7 & $0.60-0.69$ & Primary coordination \\
8 & $0.70-0.79$ & Intermediate coordination \\
9 & $0.80-0.89$ & Good coordination \\
10 & $0.90-1.00$ & Quality coordination \\
\hline
\end{tabular}




\section{Results and discussion}

\subsection{Coupling and coupling coordination analysis}

The development of financial entity, financial environment, economic growth coupling degree and coupling coordination degree has a large difference, but the development gap is gradually narrowing ${ }^{5}$. From the numerical point of view, the coupling degree of the three systems in Jiangsu Province has fluctuated but has been at a high level, and the coupling coordination degree is synchronized with the development of the comprehensive evaluation index. With the continuous improvement of the comprehensive evaluation index, the integration index of the three systems is increasing. The coupling coordination degree is gradually narrowing with the coupling degree.

Table 3 - Jiangsu Province financial subject, financial environment, economic growth coupling degree, comprehensive evaluation index, coupling coordination

\begin{tabular}{cccc}
\hline Year & Coupling (C) & Comprehensive Evaluation Index (T) & Coupling coordination (D) \\
\hline 2006 & 0.7855 & 0.1160 & 0.3019 \\
2007 & 0.9719 & 0.1944 & 0.4347 \\
2008 & 0.9955 & 0.2711 & 0.5195 \\
2009 & 0.9286 & 0.3059 & 0.5329 \\
2010 & 0.9905 & 0.4813 & 0.6904 \\
2011 & 0.9700 & 0.5366 & 0.7215 \\
2012 & 0.9196 & 0.5879 & 0.7353 \\
2013 & 0.9465 & 0.6052 & 0.7569 \\
2014 & 0.9717 & 0.6886 & 0.8180 \\
2015 & 0.9996 & 0.8242 & 0.9077 \\
\hline
\end{tabular}

In terms of coupling degree alone, the coupling effect of financial system, financial environment and economic growth system seems to be ideal. As mentioned above, the coupling degree also has its shortcomings, in order to more fully reveal the overall degree of coordination of the two systems, but also in-depth study of the coupling coordination between the two. The three systems show a good trend both in terms of coupling degree and coupling coordination degree. Coupled coordination degree achieves a leap from mild to high quality coordination.

\subsection{Comparative analysis}

In order to better analyze the influencing factors of the coupling relationship of the three systems, the coupling analysis of the binary system is introduced to account for the coupling of the three kinds of binary systems between the financial subject, the financial environment and the economic growth. On this basis, the coupling of these three kinds of binary systems is compared with that of the three systems, and the influencing factors and their characteristics 
of the coupling variation of the three systems are determined. The results of the coupling of the three binary systems are shown in Table 4.

On the whole, the coordination degree of financial system, financial subject and economic growth and financial environment and economic growth of Jiangsu Province are changed from $0.361,0.260,0.266$ to $0.910,0.902,0.910$ respectively. Financial entities and financial environment vary from mild disorder to the quality coordination; financial and economic growth and financial environment and economic growth vary from moderate disorder to quality coordination; and three system coupling degree varies from mild disorder to quality coordinated. Three systems and the binary system are maintained at the coupling level of continuous optimization, and the development of similar levels of coupling. It is shown that the relationship between the three types of two systems is consistent with the overall coupling of the three systems, and the relationship between the province's financial ecology and economic growth tends to be optimized.

Table 4 - Jiangsu province financial subject, financial environment, economic growth coupling degree, comprehensive evaluation index, coupling coordination degree

\begin{tabular}{ccccccccccc}
\hline & \multicolumn{3}{c}{$\begin{array}{c}\text { Financial Subject \& Financial } \\
\text { Environment }\end{array}$} & \multicolumn{3}{c}{$\begin{array}{c}\text { Financial Subject and } \\
\text { Economic Growth }\end{array}$} & \multicolumn{3}{c}{$\begin{array}{c}\text { Financial environment and } \\
\text { economic growth }\end{array}$} \\
\hline & $\mathrm{C}$ & $\mathrm{T}$ & $\mathrm{D}$ & $\mathrm{C}$ & $\mathrm{T}$ & $\mathrm{D}$ & $\mathrm{C}$ & $\mathrm{T}$ & $\mathrm{D}$ \\
2006 & 0.905 & 0.144 & 0.361 & 0.575 & 0.118 & 0.260 & 0.824 & 0.086 & 0.266 \\
2007 & 0.947 & 0.198 & 0.433 & 0.979 & 0.209 & 0.452 & 0.992 & 0.177 & 0.419 \\
2008 & 0.991 & 0.273 & 0.520 & 0.997 & 0.279 & 0.528 & 0.999 & 0.261 & 0.511 \\
2009 & 0.853 & 0.303 & 0.508 & 0.978 & 0.349 & 0.584 & 0.940 & 0.266 & 0.500 \\
2010 & 0.983 & 0.470 & 0.680 & 1.000 & 0.508 & 0.713 & 0.987 & 0.465 & 0.678 \\
2011 & 0.965 & 0.498 & 0.693 & 0.941 & 0.523 & 0.701 & 0.997 & 0.589 & 0.766 \\
2012 & 0.899 & 0.516 & 0.681 & 0.834 & 0.565 & 0.686 & 0.990 & 0.683 & 0.822 \\
2013 & 0.928 & 0.550 & 0.714 & 0.893 & 0.581 & 0.720 & 0.996 & 0.686 & 0.826 \\
2014 & 0.955 & 0.652 & 0.789 & 0.951 & 0.657 & 0.791 & 1.000 & 0.756 & 0.869 \\
2015 & 0.999 & 0.829 & 0.910 & 1.000 & 0.814 & 0.902 & 0.999 & 0.829 & 0.910 \\
\hline
\end{tabular}

At the same time, according to Table4 we are not difficult to find that the financial main body of Jiangsu Province and the financial environment, financial and economic growth and financial environment and economic growth of the two types of binary system coupling degree at a high level of development, indicating that each system through benign interaction, interdependence and coordination, has reached a complementary dynamic relationship. However, due to the development of the system itself, the problem of coupling coordination in the initial stage at a low level. This is also consistent with the development of the coupling system of the three systems. It shows that the coupling level of the three systems is closely related to the coupling degree of the financial entity - the financial environment, the financial subject - the economic growth and the financial environment - economic growth. 


\section{Conclusions}

This paper chooses the data of Jiangsu Province in recent years from 2006 to 2015, and analyzes the relationship between Jiangsu's financial ecology and economic growth through the construction of coupling model. In terms of the characteristics of the composite index, the three indices of Jiangsu Province show a steady upward trend, and the three are highly correlated. From the coupling characteristics, the coupling degree of the financial entity, financial environment and economic growth in Jiangsu Province is in higher level. Financial ecological development trend is good with economic growth in high quality and coordinated development. But the problems are worth thinking about: the instability of the system development led to fluctuations in the coordination degree to further affect the economic development. Through the comparative analysis, it is found that the coupling level of the three systems in Jiangsu Province is closely related to the coupling development of the three kinds of binary systems. Therefore, it can be deduced that to improve the coupling degree of financial system, financial environment and economic growth system, first we must promote the coordinated development of binary systems, thus to further promote the three systems of the level of coupling development.

\section{References}

1. Lin Yongjun. Financial ecological construction: a system based on the analysis [J]. Finance Research 08 (2005) 44-52.

2. Xiao Anfu, Xu Yanfei. A microcosmic explanation of the efficiency of financial ecology and capital allocation: a case study of Zigong [J] .Computer research 06 (2005) 154-163.

3. Study on the Evaluation Index System of Regional Financial and Ecological Environment [J]. Finance Research 01 (2006) 167-177.

4. Huang Guoping, Liu Yuhui. China financial ecological environment evaluation system design and analysis [J]. System Engineering Theory and Practice 06 (2007) 7-14.

5. Li Qian. Zibo high-tech zone of talent pool drive mechanism research [D]. China Ocean University (2010). 